\title{
Encontros e (des)encontros entre a Educação Física e a creche: análises sobre ações do Pibid
}

Encounters and (dis)encounters between Physical Education and daycare: analysis of Pibid actions

Eduarda Heydt Heinen

Marcos Aurélio Eger de Souza José Ricardo Silva

Resumo: O presente texto é um estudo de revisão do tipo estado da arte que busca na produção acadêmica relatos de experiências que contemplem ações da Educação Física aliada ao Programa Institucional de Bolsas de Iniciação à Docência (Pibid) na creche. Para tanto, alocamos a investigação na faixa temporal que compreende o início do PIBID, 2007 até o ano de 2019. Como banco de dados, optou-se pelas seguintes plataformas on line Scientific Electronic Library Online (SciELO), Literatura Latina-Americana e do Caribe em Ciências da Saúde (LILACS) e o Catálogo de teses e dissertações da Coordenação de Aperfeiçoamento de Pessoal de Nível Superior (CAPES). O resultado demonstra escassa produção sobre o tema derivado de um histórico (des)encontro entre a Educação Física e a Educação Infantil e, consequentemente do edital do Pibid. Com o intuito de contribuir com o debate, relatamos nossa experiência de encontro entre a Educação Física e o Pibid na creche. Em nossas conclusões, defendemos a atuação do professor de Educação Física na creche desde que em consonância com as concepções de desenvolvimento integral e o Pibid enquanto política pública de formação inicial e continuada de docentes como forma de superar concepções pragmáticas e mecânicas de atuação deste profissional na Educação Infantil.

Palavras-chave: Educação Física, Pibid, creche, Educação Infantil, formação de professores.

Abstract: The present text is a state-of-the-art review study that seeks, in academic production, reports of experiences that contemplate Physical Education actions combined with the Institutional Program for Teaching Initiation Scholarships (Pibid) in the daycare center. To this end, we allocate research in the time range that comprises the beginning of PIBID, 2007 until 2019. As a database, we opted for the following online platforms Scientific Electronic Library Online (SciELO), Latin American Literature and the Caribbean in Health Sciences (LILACS) and the Catalog of theses and dissertations from the Coordination for the Improvement of Higher Education Personnel (CAPES). The result shows little production on the theme derived from a historical (dis) encounter between Physical Education and Early Childhood Education and, consequently, the Pibid announcement. In order to contribute to the debate, we report our experience of meeting between Physical Education and Pibid at the daycare center. In our conclusions, we defend the role of the Physical Education teacher in the day care center as long as it is in line with the concepts of integral development and Pibid as a public policy for initial and continuing education of teachers as a way to overcome pragmatic and mechanical conceptions of the performance of this professional in Child education.

Keywords: Physical Education, Pibid, day care, Early Childhood Education, teacher training. 


\section{Introdução}

As crianças se relacionam e exploram a realidade em que estão inseridas utilizando o corpo e se movimentando. Elas fazem isso o tempo todo, consigo mesmas, entre os pares, explorando os elementos da natureza, conhecendo os objetos sociais ou imitando os adultos. Neste sentido, o corpo em si e o corpo em movimento é meio e fim pelo qual crianças desde bebês iniciam o complexo processo de apropriação da cultura humana em suas diferentes manifestações, tempos e lugares.

Este modo de viver e compreender o mundo não é diferente em âmbito institucional, ou seja, os bebês e as crianças também se relacionam assim na Educação Infantil. Esta concepção de desenvolvimento humano fez com que as atividades de corpo e movimento na Educação Infantil fosse valorizada por estudiosos de diferentes áreas e diferentes perspectivas teóricas. Dentre as áreas de conhecimento que lançaram um olhar para a Educação Infantil, queremos destacar a Educação Física.

A atual Lei de Diretrizes e Bases da Educação Nacional (LDBEN), Lei $n^{\circ}$ 9.394, publicada em 1996, disciplina a Educação Infantil, creche e pré-escola, como primeira etapa da Educação Básica. A mesma publicação oficial define a Educação Física como componente curricular obrigatório em toda a Educação Básica (BRASIL, 1996). Portanto, entende-se que a Educação Física é componente curricular obrigatório na Educação Infantil.

A discussão que se propôs neste texto surge no cerne de trabalho de um grupo de graduandos (7) de Educação Física e um professor de Educação Física recém contratado por concurso público em uma instituição de Educação Infantil da rede federal de ensino. A relação profissional entre estes indivíduos ocorre no âmbito do Programa Institucional de Bolsas de Iniciação à Docência (Pibid).

Lançado no fim de 2007 pelo Ministério da Educação, o Pibid tem como principal objetivo, o desenvolvimento da profissão do magistério. Em sua constituição, o programa envolve estudantes de diferentes cursos de licenciatura e professores formadores (professores universitários e docentes da educação básica) em ações planejadas e desenvolvidas que objetivam o 
processo de formação inicial dos graduandos e, consequentemente a formação continuada dos docentes envolvidos. Portanto, em seu movimento, o programa pretende avançar a teorização da prática educativa, os modismos educativos ou as iniciativas tácitas. Mais do que isso, o Pibid traz como principal característica a práxis docente, isto é, estudos e reflexões teóricas e a prática docente, ambas desenvolvidas no ambiente escolar.

É preciso esclarecer que, em nosso caso, graduandos e professor, não tínhamos até então, uma experiência consolidada com a Educação Física na Educação Infantil. Por esta razão, inquietações começaram a surgir em diálogos e reflexões logo nas primeiras reuniões semanais do Pibid enquanto os discentes estavam no momento de inserção e aproximação junto aos bebês e às crianças nos respectivos grupos. Dentre os graduandos, quatro se mostraram interessados em se aproximar, conhecer e estudar as vivências de Educação Física com os bebês e as crianças em idade de creche, ou seja, 4 meses a 3 anos de idade. Especificamente sobre esta faixa etária as questões levantadas entre os participantes foram: qual o papel do professor de Educação Física na creche? Como o professor de Educação Física pode atuar com os bebês e crianças de até 3 anos de idade? Quais as propostas que este profissional pode fazer para este público?

Reconhecemos enquanto grupo que todas estas perguntas seriam respondidas ao longo do tempo de trabalho no Pibid, haja vista que a natureza do programa consiste em estudos e atividades de atuação docente. Contudo, devido à falta de experiência dos envolvidos, consideramos pertinente iniciarmos os nossos trabalhos olhando para outras experiências desenvolvidas por outros grupos semelhantes ao nosso. Neste sentido, optamos em buscar e conhecer o que outros grupos de Pibid que conciliam a Educação Física na creche já haviam realizados.

No anseio por respostas para as questões levantadas optamos por estruturar uma busca de publicações de relatos e trabalhos científicos que pudessem lançar luz sobre as indagações iniciais. Entendemos que, enquanto grupo de trabalho que está em estágio inicial de práticas e estudos pedagógicos, ou seja, em processo de formação docente, em esfera coletiva e 
científica, uma aproximação sistematizada da literatura existente sobre o objeto de pesquisa anunciado, seja o primeiro passo para direcionar as reflexões, os estudos e o próprio trabalho a ser desenvolvido.

Assim, o objetivo norteador deste texto é apresentar e discutir os trabalhos já realizados por grupos de Pibid na área de Educação Física na creche. Nosso intuito com este objetivo foi de conhecer diferentes experiências desenvolvidas que poderiam lançar luz sobre nossas inquietações, diminuir as angústias e orientar os nossos passos. Com o intuito de nos aproximarmos deste objetivo, optamos por utilizar a metodologia denominada 'estado da arte' ou 'estado do conhecimento'. A caracterização da metodologia, a descrição da busca realizada e a apresentação e discussão dos dados serão feitas a seguir. Em tempo, apresentaremos um breve relato sobre algumas propostas que realizamos com bebês e crianças tendo como base o currículo institucional e o planejamento com as professoras dos grupos.

\section{A metodologia da pesquisa}

A metodologia denominada Estado da Arte, de caráter bibliográfico, tem o intuito de mapear e dialogar com as produções acadêmicas já existentes sobre um determinado tema (FERREIRA, 2002). Com essa metodologia, é possível conhecer quais são os assuntos e caminhos recorrentes ao se tratar de um determinado objeto de estudo, assim como, se aproximar de um panorama mais geral sobre a temática e identificar quais são as lacunas existentes no campo. Assim, estudos que se utilizam do Estado da Arte

[...] são justificados por possibilitarem uma visão geral do que vem sendo produzido na área e uma ordenação que permite aos interessados perceberem a evolução das pesquisas na área, bem como suas características e foco, além de identificar as lacunas ainda existentes. (ROMANOWSKI; ENS, 2006, p. 41).

A busca por artigos foi realizada em plataformas online que, consideravelmente, possuem destaque científico nacional e internacional, haja vista a avaliação de mérito científico às cegas por pareceristas de diferentes regiões do país. Além disso, tais bases foram consideradas neste estudo por 
oferecerem ao público interessado, acesso aberto a textos e trabalhos completos de pesquisas em diferentes áreas do conhecimento. Vale ressaltar que, diversas revistas com elevado extrato no qualis na área de nosso interesse, se encontram indexados nas referidas bases. A partir destas orientações, optamos por realizar as nossas buscas nas seguintes bases: Scientific Electronic Library Online (SciELO), no índice Literatura Latinoamericana e do Caribe em Ciências da Saúde (LILACS). Ainda, buscamos por teses e dissertações no catálogo da Coordenação de Aperfeiçoamento de Pessoal de Nível Superior (CAPES).

Estamos convencidos de que tais bases são representativas no que tange a difusão de trabalhos acadêmicos e, portanto, nos auxiliariam no processo de aproximação das publicações científicas de forma a contribuir para os nossos estudos enquanto grupo de trabalho que objetiva estudar as práticas pedagógicas propostas por professores e estudantes de Educação Física na creche vinculados ao Pibid.

Para orientar a pesquisa, inicialmente, o grupo de trabalho discutiu sobre quais descritores seriam utilizados para que a busca fosse fiel aos interesses do estudo. Assim, para realizar as buscas, definimos como descritores: Educação Infantil, Pibid, Programa Institucional de Bolsas de Iniciação à Docência, Educação Física, creche, bebês e crianças pequenas. Estes descritores foram pesquisados em diferentes combinações utilizando os operadores booleanos and e or, assim: (1) "Educação Física" AND "Educação Infantil" AND "PIBID"; (2) "Educação Física" AND "Educação Infantil" AND ("PIBID" OR "Programa Institucional de Bolsas de Iniciação à Docência"); (3) "Educação Física" AND ("Educação Infantil" OR "Creche") AND ("PIBID" OR "Programa Institucional de Bolsas de Iniciação à Docência"); (4) "Educação Física" AND ("Educação Infantil" OR "bebês") AND ("PIBID" OR "Programa Institucional de Bolsas de Iniciação à Docência"); (5) "Educação Física" AND ("Educação Infantil" OR "crianças pequenas") AND ("PIBID" OR "Programa Institucional de Bolsas de Iniciação à Docência"); (6) "Educação Física" AND "Creche" AND ("PIBID" OR "Programa Institucional de Bolsas de Iniciação à Docência"). 
Iniciamos as nossas buscas na plataforma Scielo. Uma a uma, cada combinação foi utilizada na busca de trabalhos. Contudo, neste repositório, não foram encontrados trabalhos que abordassem o tema de nosso interesse.

Em seguida, prosseguimos com a busca no Lilacs. Neste índice, utilizando as seis combinações anunciadas, encontramos apenas 1 trabalho (MARTINS, 2015), que abrange o nosso objeto de pesquisa, a experiência de Pibid e Educação Física na Educação Infantil.

Por último, realizamos a investigação no banco de teses e dissertações da CAPES. Esta plataforma, nos possibilitou aplicar outros refinamentos em nossas buscas. Em todas as combinações selecionamos o refinamento do período das publicações (2007 a 2019), grande área de conhecimento (ciências da saúde e ciências humanas) e área de conhecimento (educação e educação física). As combinações elaboradas por este grupo de trabalho e os refinamentos próprios do site, nos indicaram um total de 271 publicações tal como expusemos no quadro. Totalizando 272 trabalhos encontrados. O quadro abaixo apresenta, em síntese, os arquivos encontrados em cada uma das bases a partir das respectivas combinações.

Quadro 1 - Síntese dos arquivos encontrados

\begin{tabular}{|c|c|c|c|}
\hline \multirow[b]{2}{*}{ Combinação } & \multicolumn{3}{|l|}{ Bancos de dados } \\
\hline & Scielo & LILACS & Teses e dissertações \\
\hline 1 & 0 arquivos encontrados & 1 & 3 arquivos encontrados \\
\hline 2 & 0 arquivos encontrados & 0 & 184 arquivos encontrados \\
\hline 3 & 0 arquivos encontrados & 0 & 17 arquivos encontrados \\
\hline 4 & 0 arquivos encontrados & 0 & 31 arquivos encontrados \\
\hline 5 & 0 arquivos encontrados & 0 & 19 arquivos encontrados \\
\hline
\end{tabular}




\begin{tabular}{|l|l|l|l|}
\hline 6 & 0 arquivos encontrados & 0 & 17 arquivos encontrados \\
\cline { 3 - 4 } & \multicolumn{2}{|l|}{ Total: 272 arquivos } \\
\cline { 2 - 3 }
\end{tabular}

Fonte: os autores

Com estes achados, o grupo realizou uma aproximação mais detalhada dos dados. Realizamos a leitura dos títulos, resumos, palavras-chaves, introduções e considerações finais com o intuito de verificar se eles propunham discussões que abrangessem a temática aqui abordada. Este procedimento, nos levou a descartar 271 publicações haja vista que apenas a dissertação de Martins (2015) trata de forma direta do tema de nosso interesse. Este dado aponta, de antemão, para a escassez de publicações que abordam o tema aqui pesquisado.

Queremos deixar claro que as combinações e os refinamentos da plataforma Capes, nos aproximaram de trabalhos que tematizam a Educação Física na Educação Infantil ou o Pibid na Educação Física. Ainda, encontramos trabalhos que foram realizados tendo como campo de estudos ou público alvo os bolsistas e as ações desenvolvidas pelo programa Pibid, por exemplo Camargo (2015) que pesquisou o processo de encantamento de acadêmicos de Educação Física enquanto bolsistas Pibid pela docência na Educação Infantil e Zandominegue (2018) que investigou as produções culturais das crianças como eixo de articulação curricular da Educação Física com a Educação Infantil. Estas publicações foram desconsideradas enquanto objetos de nossa pesquisa por não tratarem da creche e por não relatarem práticas pedagógicas desenvolvidas pelos participantes do programa com bebês ou crianças com até 3 anos de idades. No entanto, não foram descartados como fontes de conhecimento e discussão para o grupo.

O trabalho encontrado que trata da temática aqui pesquisada, a experiência do Pibid e Educação Física na Educação Infantil foi lido na íntegra. De modo geral, podemos apresentar a dissertação de mestrado de Martins (2015) tendo como objetivo analisar ações desenvolvidas pelo Pibid na formação de professores de Educação Física que atuam na Educação Infantil. O estudioso buscou, inicialmente, conhecer e analisar periódicos que discutem a Educação Física e publicações em nos anais do Congresso Brasileiro de 
Ciências do Esporte (Conbrace) para discutir a formação de professores para a Educação Infantil e o Pibid.

Ao cumprir esta etapa inicial de seu estudo, Martins (2015) também constatou baixa produção sobre o tema. Além disso, em suas análises percebeu que a Educação Infantil não é abordada com exclusividade pelos bolsistas do Pibid, conjugando a área com outras etapas da educação básica.

Martins (2015) discutiu os elementos constitutivos do Pibid enquanto política pública e analisou as práticas pedagógicas desenvolvidas por bolsistas assistidos pelo programa no que tange concepções de infância e de criança. Sobre esta questão é interessante apontar que, enquanto avançávamos a leitura de seu trabalho, notamos uma frágil presença da pré-escola e a ausência total da creche.

O delineamento metodológico utilizado por Martins (2015) foi, então, marcado pelo uso de estado de conhecimento e, em seguida, pelo o que denominou de Pesquisa-ação Colaborativa e observação participante com o uso de diário de campo a partir de narrativas textuais e orais produzidas pelos graduandos de Educação Física enquanto atuavam com crianças. Com isso, o autor se atentou para as falas, atos e desenhos das crianças consideradas como produtoras de cultura.

Apesar de Martins (2015) abordar a experiência de Pibid e Educação Física na Educação Infantil, a faixa etária das crianças participantes da pesquisa variavam entre 5 e 6 anos de idade, a chamada pré-escola. A capoeira foi o tema proposto pelo grupo dos estudantes de Educação Física para este grupo de crianças. Isto significa, então, que o trabalho de Martins (2015) também não corresponde em totalidade com interesse do nosso grupo.

Frente a realidade constatada, nos cabe discutir teoricamente as razões postas pela realidade objetiva que distanciam a atuação de estudantes de Educação Física, assistidos pelo Pibid, atuando na primeira etapa da Educação Básica, mais especificamente na creche. Para tanto, nas próximas páginas tentaremos expor teoricamente quais obstáculos afastam a relação entre a Educação Física, o Pibid e a creche. 


\section{Encontros e (des)encontros entre a Educação Física, a Educação Infantil e o Pibid}

Para iniciarmos esta discussão há que se considerar, mesmo que de forma geral, o processo histórico que envolve a Educação Física e a Educação Infantil. Para tanto, procuraremos destacar alguns pontos que se referem a políticas públicas e concepções teóricas que proporcionam os encontros e os (des)encontros entre a Educação Física e a Educação Infantil e, consequentemente, a relação entre a Educação Física e o Pibid na creche.

A identidade da Educação Física brasileira estruturou-se de acordo com os interesses históricos e paradigmas de cada época. Sob o ideário higienista, os métodos ginásticos (ginástica sueca e francesa), marcaram a Educação Física no final do século XIX e início do século XX. Predominantemente até meados da década de 60, o modelo militarista tinha como propósito a formação de indivíduos fortes, sadios, aptos a defender a nação. Por esta razão, as aulas de Educação Física, ministradas por instrutores do exército, apresentavam caráter rígidos da disciplina e hierarquia. É ainda nesta época que emerge o modelo de aula que valorizava o ensino dos esportes. A ênfase na competição, no mais forte, mais veloz e mais habilidoso persiste em marcar a Educação Física escolar (SOARES, et al., 1992)

Olhando para as políticas públicas, na primeira versão da Lei de Diretrizes e Bases da Educação Nacional (LDBEN) a Educação Física aparece como obrigatória para o então Ensino pré-primário (maternal e jardim de infância) com a Lei $n^{\circ} 4.024$ de 1961. O Decreto $n^{\circ} 69.450$ de mesmo número de lei publicado em 1971, que regulamentou a Educação Física, remete uma perspectiva essencialmente de vivência prática, tendo a aptidão física como elemento central da área (CASTELHANI FILHO, 1998).

Neste período inicia-se um movimento popular em defesa da Educação Infantil que busca superar estigmas históricos que insistem em caracterizar esta instituição como entidade de amparo e cuidados de crianças pobres, trabalho esse realizado sobremaneira por mulheres e sem formação específica (SAYÃO, 2010). Em relação ao movimento corporal podemos apontar que, de modo geral, as crianças viveram e, por vezes, ainda vivem, experiências livres 
em que elas escolhem onde, como, com o que e com quem irão se relacionar. Nesta condição a criança age autonomamente para aquilo que lhe chama a atenção: lugares, objetos, pessoas, etc. Assim, é ela quem cria e organiza o seu próprio tempo e espaço para vivenciar corporalmente o entorno sem que haja por parte dos adultos responsáveis intenções, planejamentos, organizações, valorizações e aproximações para ampliarem as vivências infantis. Em situações assim não há promoção intencional do desenvolvimento infantil.

A partir do século XIX, a Educação Física se torna um instrumento de controle social para o Estado. Para se legitimar nas camadas burguesas e populares, recorre a ciência para dar um sentido a sua prática. Ela servia como educação do corpo, para formar pessoas dóceis, mas preparadas para servir a pátria e ao trabalho. O caráter cientificista da Educação Física se apresenta até hoje, seja como uma estratégia para garantir sua permanência na Universidade ou para garantir suas áreas de atuação junto da sociedade (BETTI, 1991). Sob essa influência, compreendemos melhor a razão de encontramos durante as nossas buscas trabalhos que tematizam o movimento na Educação Infantil em uma perspectiva biologizante, uma discussão da motricidade infantil pela biomecânica.

Compreendendo a necessidade e a importância do movimento para o desenvolvimento das crianças o governo federal faz uma série de publicações orientando sobre o brincar, os brinquedos e a cultura popular na Educação Infantil. Dentre estas publicações podemos citar ' $O$ Referencial Curricular Nacional para a Educação Infantil' (BRASIL, 1998) e 'Diretrizes Curriculares Nacionais da Educação Infantil' (BRASIL, 2010).

Enquanto isso, a Educação Física começa a pensar sobre o movimento e o desenvolvimento da criança apartada das concepções esportivistas que marcam a área. Os estudos da psicomotricidade proposta por Jean Le Bouch e a abordagem desenvolvimentista focam na aquisição e desenvolvimento de habilidades motoras desde a tenra idade como conceito principal da Educação Física (CASTELHANI FILHO, 1998). Aliada a estas ideias, a abordagem construtivista, de Jean Piaget, ganha espaço nas discussões e publicações e, 
por isso, influencia os trabalhos na Educação Infantil. A teoria construtivista marca a educação infantil brasileira valorizando o papel da cultura, das experiências autônomas e, portanto, da autonomia das crianças, ou seja, da brincadeira (FREIRE, 1989).

Mesmo que o movimento tenha sido valorizado de forma livre e espontânea como nas primeiras instituições que objetivaram salvaguardar crianças pobres ou mais contemporaneamente com as publicações oficiais que chamam a atenção dos professores sobre o tema e com as contribuições teóricas de tendências e abordagens construtivistas, entendemos que o encontro entre a Educação Física e a Educação Infantil iniciou quando houve um olhar mais atento sobre o movimento e a infância. Contudo, pesquisadores denunciam o quanto alguns professores que atuam com bebês e crianças pequenas ainda preferem a imobilidade ao movimento.

Garanhani e Nadolny (2011) ressaltam que, mesmo com orientações publicadas em documentos federais, algumas práticas desenvolvidas por professores na Educação Infantil, buscam manter uma atmosfera de ordem e harmonia, suprimindo as manifestações de movimentos das crianças. Uma repressão motora com base na ideia de que a criança imóvel poderá se concentrar e ater mais atenção ao aprendizado. Uma ideia que distancia as experiências motoras de exploração do entorno do desenvolvimento infantil. Ritcher e Vaz (2010, p. 61) complementando essa problemática apontam que,

Para além do controle do corpo nos espaços, nos tempos, da sujidade das crianças e das represálias em torno de atitudes indesejáveis, descontroles e ritmos não homogêneos dos pequenos, algumas aulas de Educação Física - mas não apenas elas - são marcadas por castigos e ameaças: avisos e repreensões, reprimendas e punições, geralmente na forma de restrição corporal, mas também por incitamentos pautados em compensações e recompensas.

É a partir da década de 1980, com transformações e aberturas políticas democráticas que surgem novos modos de pensar a Educação Física (SOARES et al., 1992). No entanto, mesmo com o surgimento de teorias críticas, a representação que a sociedade em geral ainda tem da Educação Física, reforçada por algumas práticas docentes que não se distanciam dos 
resquícios históricos, persiste a associação da área como a disciplina responsável pelo o ensino de esportes. Aparentemente, este estigma favorece um (des)encontro entre a Educação Física e a Educação Infantil.

Esta relação histórica entre o próprio desenvolvimento da identidade da Educação Física enquanto se firmava como componente curricular obrigatório da Educação Básica sofreu e ainda sofre (des)encontros com a educação dos pequenos. As vivências de movimento na Educação Infantil ainda são compreendidas como momento de recreação, para passar o tempo, de distração, de brincar ou correr sem intencionalidade. Também, é possível observar que nos municípios onde há a presença do profissional de Educação Física exercendo sua função na Educação Infantil, as propostas são, por vezes, caracterizadas como a hora do movimento repetitivo, em cadência, do circuito, atividades para desenvolver o andar, o saltar, o correr, a lateralidade, uma herança da psicomotricidade e da abordagem desenvolvimentista (SURDI; MELO; KUNZ, 2016). Por isso, não raro alguns estudiosos criticam a presença do profissional de Educação Física na Educação Infantil devido a essas características esportivistas, de movimentos estereotipados, um movimento em si, criando uma característica de escolarização disciplinar na Educação Infantil. (RITCHER, VAZ, 2010; MELLO et al. 2016).

Sob o olhar desta preocupação, as práticas docentes desenvolvidas por professores de Educação Física aparecem apartada dos interesses e concepções de desenvolvimento integral que estudos e pesquisas realizados sobre e no âmbito da Educação Infantil conquistaram ao longo do tempo. Tais estudos defendem uma concepção de criança capaz que quer se comunicar, que é curiosa, que estabelece relações com os objetos e com as pessoas enquanto se movimenta pelos espaços (SOUZA; MELLO, 2018). Um bebê que está atento ao que se passa ao redor, portanto ativo em suas relações, que ouve, olha e toca o mundo material incorporando-o cada vez mais (SILVA, 2018). Portanto, uma concepção que entende o bebê e a criança com uma capacidade de desenvolvimento que vai além das atividades de movimentos estereotipadas, repetitivas, de circuito, ou seja, pelo movimento em si. 
A publicação da última versão da LDBEN (BRASIL 1996) fez com que houvesse um aumento significativo de estudos e publicações sobre a educação de bebês e de crianças no Brasil. Com o passar do tempo, estes estudos impactam concepções e práticas pedagógicas desenvolvidas na creche e na pré-escola pelo país. Neste contexto, o movimento, objeto de estudo da Educação Física, é compreendido e valorizado de tal forma que as brincadeiras, os jogos populares, as danças e os brinquedos tornam-se representativos da Educação Infantil. Apesar da referida publicação federal considerar a Educação Física componente curricular de toda a Educação Básica, logo da Educação Infantil, a LDBEN de 1996 não obriga a presença do profissional de Educação Física para propor vivências de movimento. Este (des)encontro legal entre a Educação Física e a Educação Infantil provocado por uma política pública permite que a maioria dos municípios brasileiros não contratem profissionais de Educação Física para atuarem com bebês e crianças nas instituições de educação infantil. Assim, as atividades que tematizam o corpo em movimento ficam sob a responsabilidades de pedagogos.

E é justamente, neste ponto, que reside o (des)encontro entre o Pibid e a Educação Física na Educação Infantil. Tendo sua portaria publicada em 23 de dezembro de 2009, o Pibid, é um programa de incentivo à formação inicial de professores. O objetivo maior desta política pública é aproximar graduandos de diferentes licenciaturas de seus futuros campos de atuação contribuindo, assim, para a melhoria da qualidade da educação brasileira. Um dos requisitos básicos para que o convênio seja firmado é a presença do professor supervisor na instituição, tal como orienta o inciso sétimo, do capítulo IV, artigo quarto,

Professor supervisor é o professor da rede pública de educação básica responsável pela supervisão dos bolsistas de iniciação à docência no âmbito de sua atuação na escola de educação básica, que atenda ao disposto na Lei no 11.273 , de 6 de fevereiro de 2006.

Como visto anteriormente, a presença do profissional de Educação Física na Educação Infantil carece, em termos legal, do interesse do município. Sem a presença deste profissional, não há condições mínimas para que haja a 
efetivação do programa. O edital do Pibid exige a presença do profissional de Educação Física na instituição para receber e orientar os graduandos ao longo do período de vigência do auxílio financeiro. É este profissional que inicia a experiência docente dos graduandos de Educação Física na instituição enquanto estudam e participam de outras atividades relacionadas ao programa de formação. Portanto, se não houver a presença do profissional de Educação Física na creche, não há oferta desta política pública na creche, não havendo este encontro entre a Universidade pela Educação Física e a creche, não há publicações de estudos ou relatos de experiências. Por esta razão, não encontramos trabalhos que pudessem orientar as nossas práticas pedagógicas de Educação Física na creche, pois como afirma Martins (2015, p. 67) "[...] a produção acadêmica sobre a formação de professores de Educação Física voltada para atuação profissional na Educação Infantil, especialmente mediada pelo programa em questão, é incipiente e que precisa ser ampliada”.

Diversos trabalhos apontam para as contribuições do Pibid enquanto política pública no processo de formação inicial de professores. Rachadel et al. (2019), aponta que o Pibid auxilia positivamente na formação do estudante pois o aproxima da escola, com o campo de atuação e com referenciais teóricos que sustentam a Educação Física. Matter et al. (2019), defendem que as experiências formativas do Pibid favorecem a construção da identidade inicial docente. Os autores destacam a valorização da associação entre a teoria e prática qualificando o ato pedagógico na escola. Andrade e Simões (2016) apontam que a presença de bolsistas do Pibid na escola impacta positivamente na prática pedagógica dos professores-supervisores, visto que, a inserção dessa política pública permite um novo olhar para sua atuação, oportunidade para aprimorar conhecimentos da área e aperfeiçoar o processo de ensinoaprendizagem.

É no cerne das afirmações feitas pelos autores supracitados que defendemos a presença do Pibid enquanto política pública aliada aos professores e graduandos de Educação Física adentrando as creches brasileiras. Acreditamos que este encontro poderá romper com velhas concepções e paradigmas que marcam os (des)encontros entre as áreas. 
Entendemos que esta aproximação pode contribuir com a superação de práticas que valorizam o movimento em si quando os professores de Educação Física conhecerem concepções teóricas que defendem o desenvolvimento infantil de forma integral.

As ações de nosso grupo de trabalho não se resumiram na realização deste estado da arte. Tal como orienta o edital do Pibid, nossas ações também compreenderam a docência com os bebês e as crianças. Assim, enquanto buscávamos por publicações que pudessem iluminar a nossa caminhada, planejamos, organizamos e propomos vivências com bebês com faixa etária entre 4 meses e 3 anos de idade. No próximo tópico relatamos um pouco de nossa experiência.

\section{Uma experiência de Educação Física na creche}

A necessidade deste estudo se deu pela falta de experiência de um professor e graduandos de Educação Física com a docência na Educação Infantil. Deliberadamente, o grupo de bolsistas se dividiu, então, entre aqueles que se interessaram pela creche e outros pela chamada pré-escola. Independente do interesse em realizar o estado da arte sobre o tema e atendendo a organização do Pibid, este grupo de indivíduos também propôs Educação Física com bebês e crianças.

Para tanto, consideramos pertinente nos aproximarmos do currículo institucional com o intuito de conhecer as premissas que orientam as práticas docentes. O currículo da instituição, entendido como construção histórica e coletiva que direciona o trabalho, assume de forma clara a teoria históricocultural que tem como principal fundador Lev Semenovicht Vigotski e colaborações como Leontiev e Luria, dentre outros. Esta base teórica defende a ação direcionada e intencional do professor com seus destinatários, em nosso caso bebês e crianças, para uma formação humana omnilateral, um conceito marxista que se refere a formação humana em sua forma mais ampla, universal (MALANCHEN, 2016). De antemão, esta base teórica nos indica a necessidade do professor, indivíduo mais desenvolvido, de além de valorizar a espontaneidade da criança em criar e explorar o ambiente, planeja, organiza o 
espaço e os materiais, cria temas e conteúdos orientadores da ação infantil, propõe situações, se aproxima e dialoga e respeita o tempo de envolvimento com o conteúdo da atividade e, nesta perspectiva de trabalho, não cabe situações de movimento mecânico e repetitivo.

Apoiados em Martins (2009) e Saviani (2011), estamos entendendo conteúdo da atividade como aqueles conhecimentos representativos das conquistas humanas, a cultura sistematizada em saberes escolares. Especificamente para bebês, Martins (2009) nos ajudou a compreender que tais conteúdos são os operacionais, isto é, aqueles que ampliam as possibilidades de controle sobre si ao passo que desenvolvem funções psicológicas chamadas de superiores tais como a atenção, a memória, a percepção, a linguagem e a destreza motora. Logo, em nossos planejamentos, procuramos elaborar vivências que considerassem o desenvolvimento infantil de forma ampla de modo a contribuir para uma percepção e compreensão de si, dos outros, dos objetos e dos espaços e não reduzido ao aparato biológico. Aprendemos com os autores da teoria histórico-cultural que, "os objetivos da educação motriz da criança não podem estar limitados ao desenvolvimento físico, a exercitações de seu aparato motor" (ZAPORÓZHETS, 1987, p. 71).

A aproximação dos bolsistas nos grupos e a relação entre o professor de Educação Física e as professoras das turmas, proporcionou momentos de diálogo mais próximo entre todos os agentes responsáveis pelo planejamento de vivências para os bebês e crianças. Assim, além de considerarmos o currículo institucional, o planejamento das vivências buscou dialogar com a experiência e os temas abordados pelas professoras. Nesta relação entre o professor de sala, o professor de Educação Física e bolsistas Pibid, estabeleceu-se o respeito mútuo de modo que nenhum esteve subordinado ao outro, a preocupação era que a vivência fosse significativa para os bebês. Vale salientar que as aproximações inicias realizadas tanto pelo professor recémchegado e pelos bolsistas Pibid, foi permeado por muitas conversas para que pudéssemos entender a dinâmica de trabalho na instituição.

Dentre os pontos que mais nos chamou a atenção por se diferenciar de nossas experiências anteriores foi a questão do tempo. A atuação do professor 
de Educação Física nas outras etapas da Educação Básica é demarcada pela grade de horário, composto de quantidade de aulas e pelo tempo relógio, de modo geral, 2 aulas de aproximadamente 50 minutos. Havendo variações para menos sobretudo na Educação Infantil quando há a presença deste profissional. Na referida instituição, os dias, os horários e as vivências que se referem à Educação Física são acordados entre os professores responsáveis durante o planejamento semanal. Isto quer dizer que, não há um dia ou horário fixado em grade para o atendimento do professor de Educação Física neste ou naquele grupo. Existe a orientação de que o professor de Educação Física proponha vivências de corpo e movimento para todos os grupos, mas dependendo dos interesses dos profissionais envolvidos, os dias da semana e os horários das propostas podem variar.

Além disso, o tempo relógio não é o principal orientador do começo ou fim da proposta. Existe um horário de início previamente combinado para atender interesses diversos (montar cenários e fantasias, tempo de deslocamento de um espaço para outro, passeios externos, hora de lanches e etc.). Todavia, a regulação principal do horário de término é o envolvimento do bebê ou da criança na atividade. Isto quer dizer que algumas vivências duraram 40 minutos e outras, quase 2 horas. Sobre isso, explica Sayão (2002) que, na Educação Infantil o tempo é orientado pelo tempo lúdico, em que o envolvimento de crianças e adultos orientam a prática, esta concepção demonstra um avanço a ideia de fragmentação do pensar, agir e sentir infantil.

Amparados pelas contribuições da teoria vigotskiana entendemos que em determinados períodos do desenvolvimento algumas vivências contribuem qualitativamente mais que outras. Assim, organizamos para bebês e crianças de até 3 anos de idade tempos e espaços compostos por objetos e materiais que favoreceram a comunicação com os adultos, a manipulação de objetos e o faz-de-conta (VIGOTSKI, 2006).

O primeiro relato que iremos apresentar se deu com uma turma composta por 4 bebês com menos de 1 ano de idade, 1 professora e 2 
estagiárias ${ }^{1}$. Além destes adultos éramos ainda 1 professor de Educação Física e 4 bolsistas Pibid, ou seja, mais adultos do que bebês. Esta organização não quer dizer que a experiência relatada não possa ser realizada com mais bebês e menos adultos.

Ao longo da semana a professora responsável estava apresentando aos bebês o conto 'Alice no país das Maravilhas' utilizando livro, objetos, imagens e vídeos. No dia e horário marcado para nossa intervenção, a professora introduziu o tema 'chá com o chapeleiro maluco', ainda em sala, apresentando o trecho da história e os personagens. Ela vestia blusa colorida, saia longa e rodada que ao se movimentar emitia sons de guizos e uma tiara de galhos e folhas na cabeça. Inseriu incenso no ambiente para aguçar o olfato, adicionou sons de vento nas árvores e de animais de floresta. Para apresentar os personagens enquanto contava a história usou imagens e objetos representativos, por exemplo, relógio, chapéu e xícaras. Na interpretação utilizou de movimentos amplos, giros, onomatopeias e outros objetos sonoros como pandeiros, chocalhos e apitos de vento. Os bebês estavam sentados conosco e com os estagiários de sala.

Tomamos o protagonismo da cena quando a professora apontou para pegadas de coelho que indicavam um caminho para a área externa. Incorporando uma orelha de coelho na frente dos bebês convidamos todos para seguirem as pegadas. Caminhamos e saltitamos lentamente para fora com os bebês, alguns no colo, outros no carrinho. Ao longo do caminho destacamos as pegadas, o coelho e o relógio. Nos aproximamos de um cenário montado em baixo de uma árvore que em seus galhos mais baixo nos possibilitou suspender um teto com tecidos de cores diferentes e um voil branco com manchas de tintas. Dependurados nos galhos mais referências sobre o conto (cartas de baralho, e flores). Um conjunto de mesas e cadeiras coloridas enfileiradas, coberta com tecidos diversos marcavam o centro da cena. Sobre elas, miniaturas de plástico para compor a mesa de chá: xícaras,

\footnotetext{
1 De modo geral, as turmas possuem esta organização 1 professora e 2 estagiários que podem ser de diferentes áreas do conhecimento: Pedagogia, Psicologia, História, Letras, Museologia, dentre outros.
} 
copos, bules, pires, pratos, talheres e diferentes representações de alimentos. Pelo chão, tatames cobertos por tapetes.

Todo este cenário chamou atenção dos bebês. Nos aproximamos, incorporamos mais elementos da história (roupas e chapéus), colocamos alguns bebês nas cadeiras e outros no tapete. Nossa objetivo enquanto profissionais de Educação Física é que eles pudessem se locomover engatinhando ou ensaiando passos amparados pelos adultos na busca e na manipulação dos objetos ofertados: pegar, chacoalhar, bater, jogar, engatinhar, andar com apoios, etc.. Era perceptível o quanto os órgãos dos sentidos dos bebês foram afetados pelo cenário e pelos elementos disponíveis. Neste contexto, foi possível constatar o entusiasmo dos bebês devido ao olhar fixado nos objetos, a excitação motora de braços e pernas, a emissão de sons e o deslocamento de um ponto a outro.

Para Vigotski (2006) os objetos que compõem o entorno afetam seus órgãos dos sentidos, criando neles a necessidade de manipulação. De início uma manipulação aleatória, com o passar do tempo passam a utilizá-los conforme orienta a cultura. Assim, cria-se a necessidade de esticar o braço e segurar um objeto. Ao fazer isso supera a condição de movimentos aleatórios em direção ao desenvolvimento de um movimento com significado social. 0 bebê deixa de lançar o copo plástico e começa a levá-lo a boca como para beber água. O movimento tipicamente humano surge frente a necessidade e este precisa ser construído. Na creche, a função de criar necessidades para o movimento tipicamente humano é do professor que planeja, organiza e disponibiliza objetos e brinquedos. Sobre o desenvolvimento motor em situações como essa, Silva (2017, p. 154) explica que:

É preciso ter claro que no trabalho com bebês, o objetivo do professor está implícito na organização do espaço, na proposição de vivências. Este profissional deve ter a clareza de seus objetivos e, para atingi-los, deve organizar vivências que crie a necessidade de andar. Neste tipo de proposta, o caminhar deixa de ser um adestramento, uma repetição de movimentos sem sentidos para o bebê. Quando o objetivo está implícito na vivência, a criança reage a ele da sua forma, em seu tempo, dentro de suas possibilidades, sem que o professor precise ordenar, obrigar, dirigir a ação do bebê. 
Para outro grupo com idade entre 1 e 2 anos, preparamos um espaço com diversos materiais, brinquedos e objetos: caixas de papelão grandes e pequenas, tapetes coloridos com bonecas, bonecos e carrinhos, túneis de tecido, colchonetes almofadados, cabana de tecido, peças de encaixar, bolas grandes e pequenas, cestos com objetos diversos, tecidos dependurados como balanços e com nós para subir. Para buscá-los na sala, utilizamos pandeiro e tambor e cantamos cantigas populares, caminhamos lentamente até o espaço organizado. Ambientamos o local com música clássica.

No ambiente organizado puderam escolher com qual objeto e como manipular. Jogaram e chutaram as bolas, empilharam, derrubaram e entraram dentro das caixas de papelão, sentaram e balançaram nos tecidos e quando desmontados, foram puxados pelo chão, saltaram sobre os colchonetes, entraram e saíram dos túneis, montaram e desmontaram as peças. Enfim, um espaço planejado de forma intencional para que pudessem explorar de diferentes maneiras.

É preciso ressaltar que não queremos defender a atividade livre como premissa para a Educação Física na creche. A presença e a aproximação dos adultos é fundamental para o desenvolvimento infantil. Nas palavras de Vigotski (2006), são os adultos que irão 'emprestar' a consciência aos pequenos. Isso se dá quando os professores nomeiam os objetos e as ações, demonstram o uso social que se faz com eles, organiza as relações social entre os pares, usa a linguagem como signo para orientar a atenção, a memória e o pensamento. Assim, cria no bebê e na criança a necessidade de desenvolver a fala. Neste cenário, o desenvolvimento motor aparece inserido na complexidade das relações humanas superando o ensino pragmático e mecânico. A diferença entre abordagens de enfoque motor e esta perspectiva é o objetivo implícito na atividade: desenvolvimento omnilateral.

Finalizando o nosso relato, o passeio sobre rodas (motocas, caixote de rolimã e os carrinhos de bebês) foi oferecido para a turma de crianças com idade entre de 2 e 3 anos. Para esta proposta utilizamos uma área verde externa à instituição, uma calçada que delimita o passeio dos pedestres conectada em diferentes direções, que utilizamos como estrada. Ao longo da 
'estrada' alocamos diferentes pontos de paradas: um lava-carros contendo balde e borrifador com água, esponjas e panos para secar, um mercado com diferentes alimentos em miniatura, faixas de pedestre, um posto de gasolina com bomba de encher pneus de bicicleta e uma área de 'descanso' com objetos e brinquedos diversos.

Guiamos as crianças até a área externa usando coletes, apitos e placas de trânsito. As crianças pedalando as motocas chegaram antes e iniciaram o trajeto, os bebês nos carrinhos chegaram em seguida. Aos poucos e com os convites feitos pelos adultos, as crianças começaram a explorar os 'pontos comerciais' disponiveis: lavaram as motocas, encheram os pneus e fizeram compra nos mercados. A maioria das crianças experimentaram interpretar os papeis de consumidores e de comerciantes nos diferentes estabelecimentos. Sob a supervisão dos adultos andaram de motocas e foram puxadas no caixote de rolimã.

Vivências assim, que permitem o brincar de faz-de-conta, possibilita às crianças interpretarem papeis sociais. Ao protagonizarem, se colocam em situações de convívio social tal como os adultos, nível acima de sua zona real de desenvolvimento (VIGOTSKI, 2006). Além de pedalarem subindo e descendo a calçada, as crianças dialogaram entre os pares, 'compraram' e 'venderam', 'lavaram' e 'cuidaram' dos veículos. Nesta proposta estiveram em exercício funções psíquicas superiores como a atenção, a linguagem, o pensamento abstrato, capacidades psíquicas que não se desenvolvem se não forem requisitadas nas atividades. Um desenvolvimento integral da criança em uma proposta de Educação Física em que a motricidade humana não foi tratada de forma isolada.

Em tempo, há que se destacar que, na relação entre professor supervisor e bolsistas Pibid, estas propostas foram avaliadas. A avaliação foi por nós utilizada como instrumento de reflexão sobre a prática e ponto de partida para o planejamento de outras vivências. Ao avaliar o dia, discutimos a proposta realizada, o envolvimento dos bebês e das crianças na atividade, o papel desempenhado pelos adultos presentes, o envolvimento e a aproximação junto aos pequenos, a funcionalidade e segurança no espaço físico escolhido, 
dos brinquedos e dos objetos ofertados. A avaliação nos ajudou a crescer enquanto grupo de trabalho que esteve ao longo do tempo juntos pensando na Educação Física para bebês e crianças.

\section{Considerações finais}

Pretendemos neste texto conhecer experiências de encontro entre a Educação Física, o Pibid e a creche. Nossa falta de experiência neste campo de atuação nos conduziu para o levantamento de publicações que pudessem nos subsidiar em nossas práticas pedagógicas. Contudo, o estado da arte revelou a escassez de produções sobre a experiências análogas a nossa.

Esta lacuna deriva de estigmas históricos que provocam um distanciamento entre a Educação Física e a Educação Infantil. Alguns estudiosos da primeira etapa da educação básica criticam a presença deste profissional com bebês e crianças com o receio de incorrerem em uma escolarização disciplinar na Educação Infantil, ensino mecânico e repetitivo e uma formação humana pragmática.

Nossa apropriação ao currículo institucional, a aproximação junto aos grupos de bebês e de crianças, o diálogo permanente com as professoras e o planejamento coletivo possibilitou ao grupo maiores esclarecimentos sobre 0 trabalho em uma perspectiva integral de desenvolvimento infantil. Neste movimento, a práxis nos revelou a urgência de superação de concepções históricas acerca dos objetivos da Educação Física na primeira infância.

Em nossas reflexões entendemos a necessidade de superação de resquícios históricos que caracterizam a Educação Física como momento de recreação para as crianças. Por outro lado, também não estamos defendendo aulas de movimento repetitivo, mecânico sem sentido cultural. Não corroboramos com abordagens que fragmentam a criança entre corpo e mente e entre o tempo e a qualidade da vivência. Não é mais aceitável que a Educação Física, sobretudo na Educação Infantil, valorize os mais fortes, mais velozes e mais habilidoso - os princípios da competitividade, eficiência, performance, rendimento. 
Contrários a esta velha concepção de Educação Física, estamos pensando em uma atuação deste professor na Educação Infantil que objetive uma formação humana em suas máximas possibilidades. Logo, uma Educação Física que assume um papel de campo de conhecimento que, junto a outros na instituição possa propor aos bebês e crianças vivências que promovam o desenvolvimento omnilateral. Sob esta orientação, defendemos o protagonismo do professor como profissional que planeja, organiza, disponibiliza tempo, espaço, objetos, brinquedos e empresta a sua consciência aos bebês e as crianças quando se aproxima e fala com eles. O professor é o indivíduo mais experiente que guia o desenvolvimento ao propor vivências que afetam os órgãos dos sentidos e cria necessidades para o movimento desde a creche.

Nesta relação, precisamos compreender que o tempo de atenção e apropriação que os bebês e crianças pequenas investem na vivência, é diferente do tempo do adulto, um tempo marcado pelo relógio, pela produção capitalista. Para a infância, defendemos um tempo de viver, de ser, de conhecer, de explorar, de rir e de chorar, um tempo de encontro com a vida em desenvolvimento. Bebês e crianças se humanizam enquanto vivem e a qualidade de seu desenvolvimento depende de suas vivências e do quanto ela está envolvida, presente, mergulhada como sujeito nesse processo. Daí a importância do professor que está próximo observando, que pergunta, e convida para outras aventuras.

Vimos na experiência do Pibid meio e forma para possibilidades de fomentar a formação inicial e continuada de professores de Educação Física na/para a Educação Infantil em uma perspectiva integral. Esta política pública aliada à Educação Física, precisa se aproximar da Educação Infantil. Esta experiência formativa evidenciou a escola infantil como campo de trabalho coletivo necessário para a emancipação de todos os envolvidos. Longe de esgotarmos o debate, devemos continuar a caminhada no campo científico e político para que consigamos superar velhas concepções que distanciam campos de saberes que podem se complementar e elevar a educação pública brasileira. 


\section{Referências}

ANDRADE A. P. S. de; SIMÕES R. O impacto do PIBID-Educação Física na prática pedagógica de professores-supervisores. Quaestio, Sorocaba, SP, v. 18, n. 3, p. 847-865, nov. 2016. Disponível em: file://C:/Users/Jose\%20Ricardo/Downloads/2856-Texto\%20do\%20artigo-57281-10-20161125.pdf Acesso em: 27 de maio de 2019.

BETTI, M. Educação física e sociedade. São Paulo: Editora Movimento, 1991.

BRASIL. Ministério da Educação. Lei n. 9.394, de 20 de dezembro de 1996. Estabelece diretrizes e bases da educação nacional. Diário Oficial da União, Brasília, v. 134, n. 248, p. 833-841, 1996.

Ministério da Educação. Secretaria de Educação Fundamental. Referencial curricular nacional para a educação infantil / Ministério da Educação e do Desporto, Secretaria de Educação Fundamental. Brasília: MEC/SEF, 1998.

. Ministério da Educação. Secretaria de Educação Básica. Diretrizes curriculares nacionais para a educação infantil/Secretaria de Educação Básica. Brasília: MEC, SEB, 2010.

CAMARGO, M. O encantamento pela docência na Educação Infantil: Um estudo com acadêmicos de Educação Física do PIBID/CAPES-UFPR (20122014). 2015. 209 f. Dissertação (Mestrado) - Curso de Educação, Universidade Federal do Paraná, Curitiba, 2015. Disponível em: <file:///C:/Users/Vá/Desktop/PIBID\%20-

\%20NDI/Textos\%20de\%20apoio/M15_MICHAELA\%20CAMARGO.pdf>.

Acesso em: 29 ago. 2019.

CASTELLANI FILHO, L. Política educacional e educação física. Campinas: Autores Associados, 1998.

FERREIRA, N. S. de A. As pesquisas denominadas "estado da arte". Educação \& Sociedade, S.I., v. 23, n. 79, p.257-272, ago. 2002. Disponível em: <http://www.scielo.br/pdf/es/v23n79/10857.pdf>. Acesso em: 22 maio 2019.

FREIRE, J. B. Educação de corpo inteiro: teoria e prática da Educação Física. São Paulo: Scipione, 1989.

GUARANHANI, M. C.; NALDONY, L. de F. O movimento do corpo infantil: uma linguagem da criança. São Paulo: Cultura Acadêmica, Unesp - Pró-Reitoria de Graduação, Univesp, 2011. Disponível em: https://acervodigital.unesp.br/bitstream/unesp/337954/1/caderno-formacaopedagogia_8.pdf. Acesso em: 22 fev. 2019.

MALANCHEN J. Cultura, conhecimento e currículo. Autores Associados, Campinas, 2016. 
MARTINS L. M. O ensino e o desenvolvimento da criança de zero a três anos. (In) ARCE, A.; MARTINS, L. M. Ensinando aos pequenos: de zero a três anos. Campinas: Alínea, 2009.

MARTINS, R. L. R. O Pibid e a formação docente em Educação Física para a Educação Infantil. Dissertação (mestrado) Universidade Federal do Espírito Santo, Vitória, 2015.

MATTER P. C. R. et al. Pibid Educação Física: experiências na formação de professores. Motrivivência, (Florianópolis), v. 31, n. 60, p. 01-18, outubro/dezembro, 2019. Universidade Federal de Santa Catarina. Disponível em: $\quad$ https://periodicos.ufsc.br/index.php/motrivivencia/article/view/21758042.2019e59669/41717 Acesso em: 27 de abril de 2019.

MELLO, A. S. et al. A Educação infantil na Base Nacional Comum Curricular: pressupostos e interfaces com a Educação Física. Motrivivência, Santa Catarina, v. 28 , n. 48 , p. 130-149, setembro/2016. Disponível em: https://periodicos.ufsc.br/index.php/motrivivencia/article/view/2175-

8042.2016v28n48p130/32567 Acesso em: 13 de abril de 2019.

RACHADEL et. al. Pibid na Educação Física: formação e intervenção de professores. Caderno de Educação Física e Esporte, Marechal Cândido Rondon, v. 17, n. 1, p. 77-85, jan./jun. 2019. Disponível em: file:///C:/Users/Jose\%20Ricardo/Downloads/21702-83268-2-PB.pdf Acesso em: 13 de jul de 2019.

RICHTER A. C.; VAZ A. F. Educação Física, educação do corpo e pequena infância: interfaces e contradições na rotina de uma creche. Movimento, Porto Alegre, v. 16, n. 01, p. 53-70, janeiro/março de 2010. Disponível em: https://seer.ufrgs.br/Movimento/article/view/7565 Acesso em: 07 de mar. De 2019

ROMANOWSKI, J. P.; ENS, Romilda Teodora. As pesquisas denominadas do tipo "estado da arte" em educação. Diálogo Educacional, Curitiba, v. 6, n. 19, p.37-50, set. 2006. Disponível em: https://periodicos.pucpr.br/index.php/dialogoeducacional/article/view/24176/228 72 Acesso em: 22 de maio de 2019

SAVIANI, D. Pedagogia histórico-crítica: primeiras aproximações. 11.ed.rev. Campinas, SP: Autores Associados, 2011.

SAYÃO, D. T. Não basta ser mulher... não basta gostar de crianças... "Cuidado/educação" como princípio indissociável na Educação Infantil. Educação, Santa Maria, v. 35, n. 1, p. 69-84, jan./abr. 2010. Disponível em: https://periodicos.ufsm.br/reveducacao/article/view/1604 Acesso em: 01 de outubro de 2019.

. Infância prática de ensino de Educação Física e educação infantil. In: VAZ, Alexandre F.; SAYÃO, Deborah. T.; PINTO, F. M. (Org.). Educação do corpo e formação de professores: reflexões sobre a prática de ensino de Educação Física. Florianópolis: Editora da UFSC, 2002. 
SILVA, J. R. O movimento do bebê na creche: indício orientador do trabalho docente. FCT Unesp Presidente Prudente, tese (doutorado), 2017.

Contribuições da teoria histórico-cultural para a compreensão do bebê como sujeito ativo. (In) SILVA, J. R; SOUZA R. M. de; MELLO, S. A.; LIMA V. G. de. Educação de bebês: cuidar e educar para o desenvolvimento humano. Pedro \& João, Rio Claro, 2018.

SOARES, C. L. et al. Metodologia do ensino da Educação Física. São Paulo: Cortez, 1992.

SOUZA R. M. de; MELLO, S. A. O desenvolvimento cultural na infância de 0 a 3 anos: entre o cuidado e a educação. (In) SILVA, J. R; SOUZA R. M. de; MELLO, S. A.; LIMA V. G. de. Educação de bebês: cuidar e educar para o desenvolvimento humano. Pedro \& João, Rio Claro, 2018.

SURDI, A. C.; MELO, J. P.; KUNZ, E. O brincar e o Se movimentar nas aulas de Educação Física infantil: realidades e possibilidades. Movimento, Porto Alegre, v. 22, n. 2, p. 459-470, abr./jun. de 2016. Disponível em: https://seer.ufrgs.br/Movimento/article/view/58076. Acesso em: 22 de jun de 2019.

VIGOTSKI L. S. Obras escogidas. Tomo IV. 2. ed. Madrid: Machado Libros. 2006.

ZANDOMÍNEGUE, B. A. C. As produções culturais das crianças como eixo de articulação curricular da Educação Física com a Educação Infantil. 2018. 345 f. Tese (Doutorado) - Curso de Educação Física, Universidade Federal do Espírito Santo, Vitória, 2018. Disponível em: <http://repositorio.ufes.br/bitstream/10/10770/1/tese_12716_Tese\%20-

\%20Beth\%c3\%a2nia\%20Alves\%20Costa\%20Zandom\%c3\%adnegue20190114 -70020.pdf>. Acesso em: 29 ago. 2019.

ZAPORÓZHETS A. V. Importância dos períodos iniciais da vida na formação da personalidade infantil. In DAVIDOV, V. e SHUARE, M. (orgs) - La Psicologia Evolutiva y Pedagógica en la URSS (Antologia). Moscou: Editorial Progresso, 1987.

\section{Sobre os autores}

\section{Eduarda Heydt Heinen}

eduardaheinen@gmail.com

É graduanda em Licenciatura em Educação Física pelo Centro de Desportos da Universidade Federal de Santa Catarina - Florianópolis, SC.

\section{Marcos Aurélio Eger de Souza}

marcosaurelioedf@gmail.com

É graduando em Licenciatura em Educação Física pelo Centro de Desportos da Universidade Federal de Santa Catarina - Florianópolis, SC. 


\section{José Ricardo Silva}

ricardosilvaunesp@gmail.com

Possui Licenciatura Plena em Educação Física (2005) pela Faculdade de Ciências e Tecnologias (UNESP) Presidente Prudente - SP e Pedagogia (2016) pela Universidade de Jales (UniJales), Pós-graduação nível Lato Sensu em Educação Infantil (2009), Mestrado em Educação (2012) e Doutorado em Educação (2017) pela Faculdade de Ciências e Tecnologias (UNESP), Presidente Prudente - SP. Atualmente é professor de Educação Física do Ensino Básico, Técnico e Tecnológico no Instituto Federal de Educação, Ciência e Tecnologia de São Paulo, Campus Presidente Epitácio. 